\title{
Holocene Environmental Catastrophes in South America: From the Lowlands to the Andes
}

\author{
Miramar, Córdoba, Argentina, 11-17 March 2005
}

How can we unravel the environmental consequences of natural changes from those induced by human actions? How can we better understand the complex interaction between catastrophes and society? What is the important message and how to convey it to end-users and governments? These and other questions were at the core of our conference organized by the Research Center for Geochemical and Surficial Processes, University of Córdoba (Argentina) and the Department of Geography and Earth Sciences, Brunel University (U.K.).

We planned the meeting to bring Quaternary scientists, archeologists and end-users together to make a "bridge" between the environmental events/shifts since the beginning of the Holocene and the current situation, and to examine the state-of-the-art of paleoclimate research in South America. Eightyfive participants from 11 countries met in Miramar by the coast of Laguna Mar Chiquita in central Argentina. During the four-day meeting, participants had the unique opportunity to discuss the human dimension of paleoclimate research and to observe the vulnerability and reaction of Miramar inhabitants facing recent and dramatic lake water-level rises ( $8 \mathrm{~m}$ in 10 years, Fig. 1).

Invited lecturers and conference sessions addressed:

1. Natural system responses to environmental change and sustainability

2. Catastrophes and the archeo-

logical record. Holocene events and cultural consequences

3. Holocene fire history records

4. Rapid geological change

5. High resolution and co al changes

7. Holocene climate changes

The program included an excursion to the flood-affected areas of Miramar. A video documenting the demolition of the flooded portion of the village documented the psychological impact. A post-meeting field

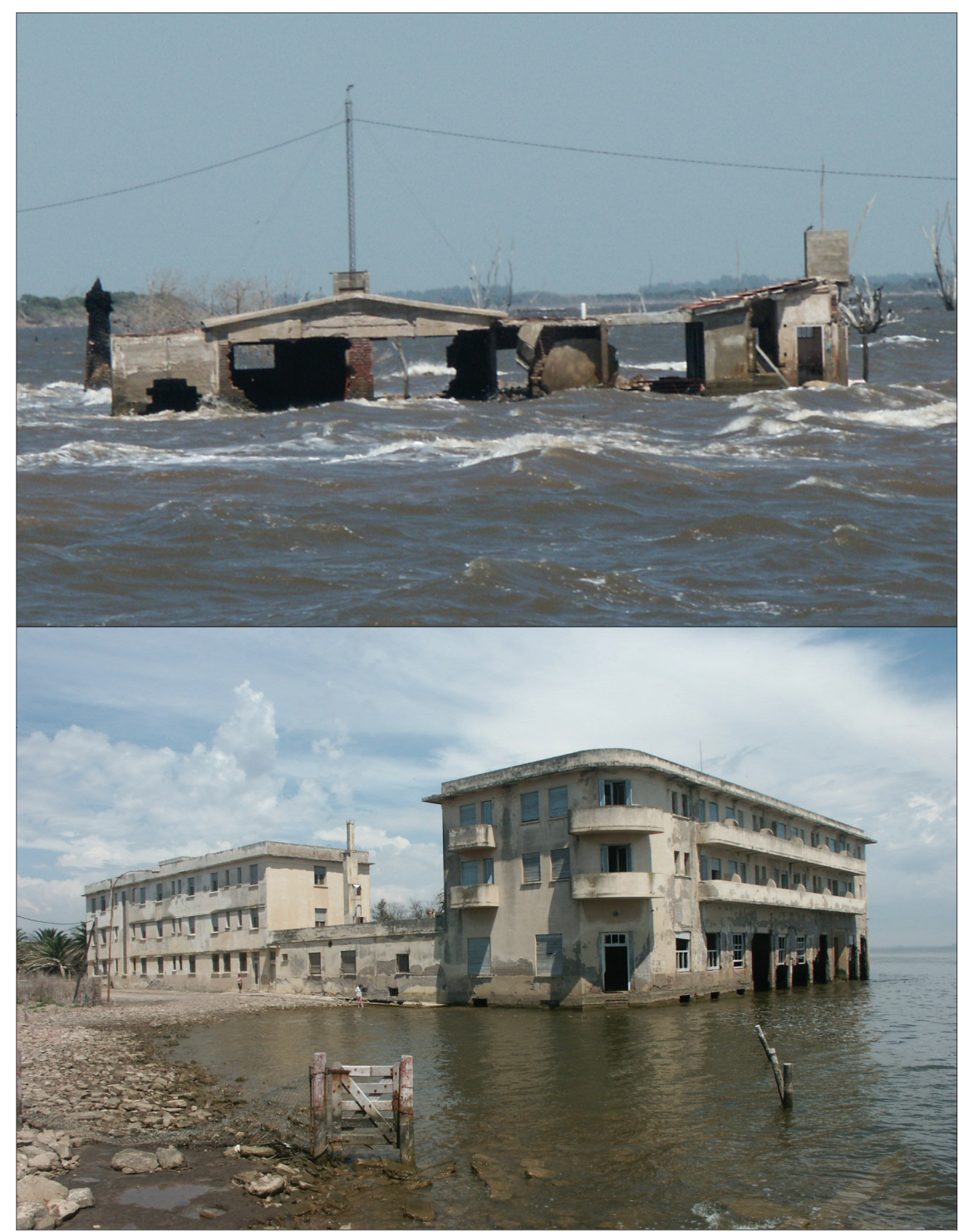

Fig. 1: Upper panel - Present-day scenario in Laguna Mar Chiquita. A highstand has dominated since 1977, producing drastic economic and social consequences. Lower panel - The program included an excursion to flood-affected areas of Miramar and the abandoned "Hotel Viena," a relict of past-flourishing times during low lake-levels. The last highstand of Laguna Mar Chiquita strongly disrupted the tourism-based local economy.

trip was focused on the evaluation of positive/negative feedbacks of comparatively higher precipitation on erosive processes and agricultural activities in the Pampas, the consequences of a catastrophic flood event, and a general view of Quaternary fluvial deposits and loess.

Several presentations showed that the 20th century climatic variability in a wide and very productive region of SE South America is represented by contrasting hydrological scenarios. Dry intervals character- ize the first 75 years, while a rise in precipitation has occurred after the 1970s. The wet phase now affecting Argentine Pampas has increased the provision of services with a market value (i.e., food and fibre) but has also seriously impacted on the quality of other non-marketable natural services and resources (i.e., erosion control, fresh water supply, biodiversity, biogeochemical cycles). Paleoclimate reconstructions show that the present positive P-E balance has had no equivalent since the Early Holocene when there was 
probably no human influence in the area.

Results point towards the necessity to reinforce paleoclimate research to fully appreciate natural climate variability beyond the instrumental record and to plan future strategies leading to sustainable development. Efforts should concentrate on bridging the gap between geoscientists and policy-makers and government agencies, persuading the latter two groups about the significance of our research for improving long-term planning actions. Geoscientists alone cannot seal the gap. One strategy could be to involve social scientists and economists in our projects, to de- code our findings to the end-users and politicians.

This conference successfully established new contacts between scientists from Latin America, North America and Europe. The scientific outcome will take the form of a special issue in the journal "Quaternary International" edited by E. Piovano, R. Villalba and S. Leroy. The meeting was sponsored by IGCP-490 (The role of Holocene environmental catastrophes in human history), ICSU/ IUGS (Dark Nature) and a number of Argentinean agencies including CONICET and FONCYT. The International Association of Sedimentologists, the Inter-American Institute for Global Change Research, the
IUGS-Geoindicators Initiative and ICSU project provided funding to 26 participants from Argentina, Brazil and Chile.

The volume of abstracts is available at: http://www.efn.uncor.edu/ investigacion/ciges/Meeting/index $\% 20$ mar\%20chiquita\%20meeting. htm.

\section{Eduardo Piovano}

CIGES, Cordoba, Argentina

epiovano@efn.uncor.edu

\section{Suzanne Leroy}

Brunel University, Uxbridge, UK

suzanne.leroy@brunel.ac.uk

\title{
Sub-aerially Exposed Continental Shelves Since the Middle Pleistocene Climatic Transition
}

\author{
INQUA InTERnational Workshop, Hong Kong SAR, China, 9-13 May 2005
}

This workshop, held at the University of Hong Kong, forms part of a 3-year project aimed at the study of sub-aerially exposed continental shelves since the Middle Pleistocene climatic transition. It was attended by 47 participants from 15 countries over 4 days with an additional fullday excursion to Lantau Island. There were 8 keynote addresses covering topics ranging from exposed carbonate shelves (L. Collins), speleothems (F. Antonioli), luminescence dating (A. Wintle), climate change and human migration (A. Montenegro), sea-level studies (Y.Yokoyama), Wanganui Basin (B. Pillans), cosmogenic radionuclides (D. Fink), and geochemical evidence (A. Chivas). A special address was also given to review the results obtained through coastal infrastructural developments in Hong Kong, where 5 interglacialglacial cycles similar to those in the Vostok ice core have been identified (W.Yim).

Sub-aerially exposed continental shelves provide evidence of climate and sea-level change. Because of the marginal location, continental shelves show features unique to both truly terrestrial and truly marine environments, and are therefore important for high resolution land-sea correlation. Other topics

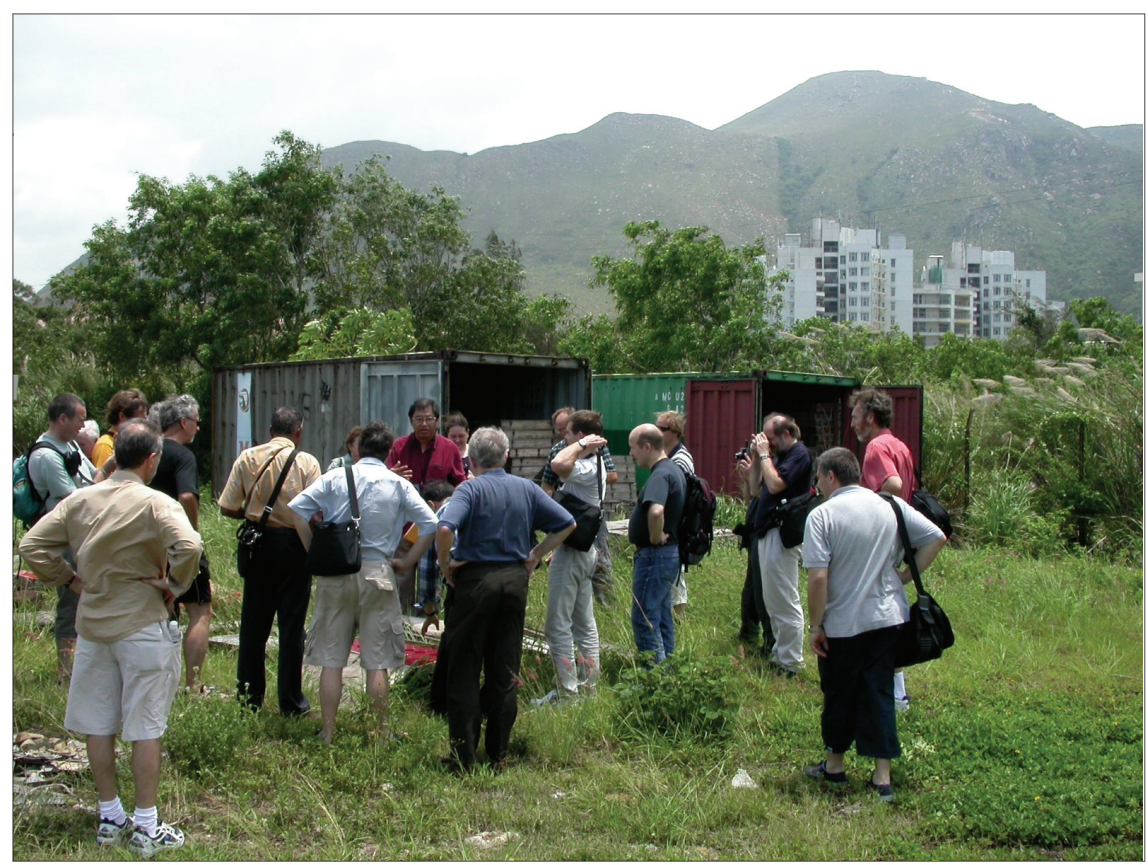

Fig. 1: Field excursion stop to examine offshore cores in a shallow bay showing evidence of 4 interglacial-glacial cycles. Photo taken by Dr S. Yang.

discussed included paleosol development, greenhouse gas production, landslide deposits, fluvial deposits, eolian deposits, geotechnical properties of sea-floor sediments, and the applicability of a range of dating methods for future investigations.

Current plans are to hold the 2006 field meeting either in Western Australia, eastern India, or southern Italy. Finalized details will be announced at a later date. In 2007, a symposium is planned for the 17th INQUA Congress in Cairns, Australia.

\section{ACKNOWLedgements}

This workshop was sponsored by INQUA, the Dr Stephen S.F. Hui Trust and the Department of Earth Sciences, University of Hong Kong.

\section{W.W.-S. YIM}

University of Hong Kong, China wwsyim@hku.hk.hk 